\title{
Analysis of Mechanical Engineering Design and Quality Control
}

\author{
Nanwu Cai \\ Jingchu University of Technology, Jingmen, 448000, China
}

\author{
Keywords: Mechanical engineering. Design. Quality control. Analysis
}

\begin{abstract}
Mechanical engineering is an important division in manufacturing engineering and machine manufacturing is a mainstream industry in manufacturing industry. While design, functioning as soul that directly affects the future mechanical quality, becomes very significant. The quality and the requirement specifications should be fully taken into account at the initial stage of design. The schemes and the ideas should be multiply examined before they are put into production. The quality control of the later period, as a judge of design, works to ensure the qualification of products. This essay mainly focuses on the analysis of mechanical engineering design and quality control.
\end{abstract}

\section{Introduction}

Mechanical engineering design serves as a basic step of machinery production and the realization of product innovation, as well as the source of implementation of quality control. Designers should not only work to ensure the products with producibility and economy property, but also the practicability under the premise of science and innovation. To achieve the purposes above, the requirements of the mechanical engineering design meeting the standard of quality control must be satisfied, and quality control of all levels must be completed before the formal production. The design and schemes of a project are main factors that concern and weigh the project quality. The quality result of the later stage can truly reflect the design effect for the mechanical engineering design. Both are interdependently related and adverse effects can be produced by their results.

\section{Quality control in the early design stage}

\section{Quality control in the design input stage}

Contents of mechanical engineering design input stage mainly include the craft package with patent nature, design documents for producing, design basis and technical information and the data of basic design, as well as the specific design requirements made by users.

These documents and requirements must go through the review and approval by professional designers or project before the next-step work begins. Since it is in the initial design stage, greater requirements are necessary for the quality, demands and rationality of the documents, along with the integrity of the design input. All departments have to pay great attention to and take active part in the stage. In other words, design input is the fundamental requirement of the design work and the initial stage of the quality control, which is directly related to the follow-up work of product quality, design schedule and the design appraisal. The materials involved in engineering design including the contract documents, design specification and craft published documents, preliminary interface figures and the contract appendixes, feasibility reports and so on should also be examined and verified to guarantee all indicators and requirements conforming to the design status and having feasibility, and be handed in to the relevant departments and the persons in charge for final review and signature after all the work has been done. Problems about quality if found in the design must be corrected and modified directly and their eligibility test after modification must be guaranteed.

\section{Quality control in the design interface stage}

According to the form of design interface, it can be divided into two types, organization and technology. The organization interface refers to the design department shall regularly have an effective joint checkup about design with the company's departments of management, procurement 
and work area, thus ensuring the effectiveness of the cooperation between departments, as well as the smooth design work. Technology interface means the design's domains make conditional transfer and adjustment in the process, of which include interface table's offer, review, modification, affirmation and reception of the design technology. The quality control of design interface requires not only effective quality control measures, systems and methods, but also great coordination between departments, which is the key to the smooth operation of the whole design, so different departments must have their clear and specific responsibilities and work harmoniously. In addition, scientific, reasonable and effective interface management programs are indispensable to quality control. Butt-joint between different departments in practical work must be implemented strictly in accordance with the stipulations of the program so as to ensure the order of interface process, the feasibility of quality control and the effectiveness of the butt joint quality to the full extent.

The work area interface of organization interface specifically involves the arrangement of work-starting meeting, the layout of designers, the initial completion of the general diagram and the detailed division in the engineering design stage. Design director should foresee possible problems in design in the meeting process, formulate detailed work plans and coordinate design tasks between domains and departments. For the device and layout of mechanical design, designers should make preliminary pipeline design on the basis of the design material and the demands of the customers at this stage, then hand the drawings to professionals to make feasibility analysis and confirm the work of the next stage. Besides, the preliminary general diagram should also be given to customers for preliminary review and when it is passed design department shall make formal design arrangements and detail-adjustments.

\section{Quality control in mid-term design}

\section{Quality control in design review}

Quality control in design review lies firstly in the embodiment of functionality in meeting the practical requirements, including the designed machines both meeting the need of practical production and efficiently matching up to and forming with other machines in the factory so as to help the enterprise achieve large-scale production and sustainable use of machines and equipments. Secondly is affirmation of the safety, credibility of the mechanical design, of which safety referring to the mechanical devices in the scene not only can satisfy natural disaster resistance of the design and quality control, but achieve the good properties of anti-explosion, fire prevention and anti-corrosion. The fulfilling of these conditions not only reduces the risks of the workers' actual operation or production, but also avoids the irreversible economic losses incurred by equipment failure when users use it. What's more, the feasibility of quality control of mechanical design mainly means that the basic data for the equipment should be accurate, complete and reasonable. If the user demands verification report, the simulation analysis or material certificate and so on provided in the design scheme, designers should present them completely, accurately and timely. Finally is the practical and economical quality control for mechanical design review, of which the former means whether the designed machines can meet the actual dismantling and the transportation requirements. Timely adjustments should be made and scheme confirmed if there is an overweight or over-transport phenomenon. The realization of economy property includes two aspects of cost control and the accomplishment of the design goals, ensuring both advanced nature and innovation of the mechanical design, and the satisfaction of the yield rate and economic treatment.

\section{Quality control in design sign}

The quality control in design sign is an important part in the whole control process, and is also the key link to ensure the accurate cooperation and reasonable control in the above each stage.In this process, quality control personnel can eliminate or explanation misunderstanding, leak, or fault which generated in the previous link. Including comprehensive sign and professional sign two parts ,the former mainly includes the reasonable layout of the mechanical design and the inspection to spatial arrangement , and the latter is aimed at the conformance between the actual design and file specification.If the design file does not meet the requirements of users or design documents, 
responsibility identification and quality improvement should be done . In addition, the time to sign must be arranged reasonably by design director; the sign of design drawings in relevant profession should be carried out in the completion stage of the drawings, and the quality problems should be timely solved or feedback in the process of sign.On the premise of ensuring the quality of design documents meet the requirements, as far as possible to save time and put forward reasonable solution, etc.

\section{Quality control in design confirmation and output}

Design confirmation is an important aspect to ensure the preciseness and repeatability of quality control.This process is carried out alone after completing the sign, which ensures that the results of the final design will not be influenced by the last confirmation work, and embodies its objectivity fully. Followed by the design output includes the printing and distributing of design drawings, material list,mechanical operation manual,site operation documents, instructor,quality standard and other documents.Although it marks the smooth completion of the design work, in the actual operation process still need to pay attention to avoid the quality control problems of plot errors, issued not in time or unqualified construction standard and so on. For the printing and distributing of design documents also must be approved by the design department and recorded by output department's, etc. This can guarantee the integrity of the design documents,but also ensures the confidentiality.

\section{Quality control in design later}

\section{Quality control in design change}

Mechanical engineering design change includes user, site and significant change.Design change that put forward by the user should communicate and confirm the feasibility with design. According to the strict variation procedure,this only can be completed under the premise of mutual consent.For the scene change requires the parties to accredit representatives with professional background and knowledge,who should determine the change responsibility and issue engineering change notice,etc.It needs general manager or design director sign before they can continue to design change if there is no site representative.Major design change means some influential aspects for mechanical operation, project implementation, progress to complete or charge additional.The change not only should be approved by the relevant department or director, but we also need to organize project personnels to audit and eventually determine whether change is feasible.The entire quality control of change process is not only to clear the corresponding responsibility and feasibility analysis, but at the same time also need to negotiate or add cost that caused in the process of design change.In addition ,the detailed records of design change have a great significance to provide effective objective evidence and confirm the quality control target.

\section{Quality control in design information feedback}

Quality control in design information feedback belongs to the last link of the whole process.Fundamental purpose is to collect and analyze feedback information from users or review units, and improve design deficiencies or defects on the basis of summarizing the successful experience. The information of this part mainly includes the local operating data of mechanical equipment , the situation of acceptance, put into operation and customer response, etc. Though these information will help design department to improve methods or provide research basis, the specific analysis work should be done by management department, and finally make a responsibility assignment or put forward improved methods, measures and regulation, etc.

\section{Conclusion}

Through the simple introduction above for the quality control in mechanical design,not only deepen the understanding to the importance of quality control from the aspects of design process,but also have a more in-depth understanding to the implementation mode of quality control in the design process. Although the quality control in mechanical engineering design is still in its primary exploration stage now in our country, we believe quality control in mechanical engineering design 
will reach a higher level in the future with the improvement of the quality control measures and related procedures.Mechanical engineering design is to ensure that the project can accord with the requirements, and meet the demand of people as one of the main factors. In order to achieve high quality of mechanical engineering, design idea and scheme need a reasonable thinking and review.After determine the correct, it can be put on production. Of course, the late work of mechanical design is machinery manufacturing, and the quality control in production is also very important. Can execute the design scheme reasonably, which is the important guarantee to ensure the quality of late work.

\section{References}

[1] Zhihua Zeng, Weijian Yu: The application of ANSYS structure optimization technology in mechanical design, Aeronautical Manufacturing Technology, 2011(10):108-113

[2] Huaidong Xie, Fengping Guan, Lipeng Wen: The mechanical design of CYCIAE - 100 cyclotron radial plug-in probe target, China Institute of Atomic Energy Annals, 2011(01):42

[3] Tao Cui, Yinlong Lv: The improvement in main magnet mechanical design of medical cyclotron, China Institute of Atomic Energy Annals, 2011(01): 58 